\title{
Design of Stable Spans at Tau Lekoa Mine
}

\author{
M.J. Dunn Newmont Asia Pacific, Australia and University of the Witwatersrand, South Africa \\ T.R. Stacey University of the Witwatersrand, South Africa
}

\begin{abstract}
Large hangingwall instabilities have been a problem at Tau Lekoa mine since stoping commenced in 1991. Crush pillars are used to prevent these by limiting spans. Spans between the crush pillars are designed to limit the potential fallout height to a thickness that is controllable by means of internal stope support. The design is based on the empirical relationship between the span and fallout height which is poorly correlated and observed thicknesses often deviate significantly from the design prediction. This paper presents results from a statistical back analysis of 81 large instabilities and includes various geotechnical and mining aspects. Probabilistic keyblock analyses have been conducted to assess the hazard associated with different pillar spans, mining directions and support systems.
\end{abstract}

\section{Introduction}

Tau Lekoa Gold mine (AngloGold Ashanti Ltd) is situated $170 \mathrm{~km}$ southwest of Johannesburg, South Africa. The Ventersdorp Contact Reef (VCR) is exploited at depths between 900 and $1650 \mathrm{~m}$ below surface (Dunn, 2003). Due to the geological complexity of the area, a scattered mining strategy with pre-developed access tunnels is employed on the mine. Stoping operations take place on strike with raise lines spaced $180 \mathrm{~m}$ apart on strike. The mine has experienced problems with large hangingwall instabilities since production began at the mine in 1991 .

\subsection{Geological and geotechnical environment}

The VCR is a conglomerate reef and at Tau Lekoa lies unconformably on the Gold Estate Formation which is part of Central Rand Group of the Witwatersrand Supergroup. It is overlain by lavas of the Klipriviersberg Group of the Ventersdorp Supergroup. The orebody is tabular dipping at $\pm 30^{\circ}$ towards the northwest. The channel width varies between 0.1 and $3 \mathrm{~m}$ and reef rolls are common. Several major faults striking northeast to southwest and dipping southeast are present.

Quartz and calcite veins are common and flat dipping veins are often associated with ground control problems such as wedges or dome structures. Several joint sets have been identified and the details are shown in Table 1. In some areas a mylonite filling is present between the lava and the VCR and this is associated with a faulted contact between the lava and VCR. This faulting is also associated with pilloidal and lensoid structures within the lava hangingwall.

Table 1 Joint information summary (Dunn and Stacey, 2006)

\begin{tabular}{ccccccc}
\hline Set & Dip $\left(^{\circ}\right)$ & \multirow{2}{*}{ Dip } & \multicolumn{4}{c}{ Spacing $(\mathrm{m})$} \\
\cline { 4 - 7 } & & Direction $\left(^{\circ}\right)$ & Mean & Std. Dev & Minimum & Maximum \\
\hline 1 & 79 & 103 & 3.17 & 1.89 & 0.67 & 8.37 \\
2 & 39 & 93 & 2.70 & 1.18 & 1.20 & 4.80 \\
3 & 80 & 142 & 5.04 & 4.66 & 1.37 & 13.30 \\
4 & 89 & 222 & 0.80 & 0.49 & 0.13 & 1.92 \\
5 & 89 & 70 & 1.55 & 0.80 & 0.40 & 3.33 \\
\hline
\end{tabular}


Stress measurements conducted at a depth of $1200 \mathrm{~m}$ indicated the following (Lombard, 1989):

- A near vertical major principal stress of 30 to $40 \mathrm{MPa}$.

- Relatively high horizontal intermediate principal stress of similar value orientated approximately north to south.

- Low horizontal stress acting approximately east to west.

The lava hangingwall uniaxial compressive strength varies between 185 and $330 \mathrm{MPa}$ (Lombard, 1989; Fourie, 1999) and the footwall quarzites range between 150 to $220 \mathrm{MPa}$ (Lombard, 1989).

\subsection{Background of large hangingwall instabilities}

Shortly after mining commenced in 1991, the first large hangingwall instabilities occurred at spans of $\pm 30 \mathrm{~m}$. Down-dip mining with pillars and timber composite packs was the initial mining method. Additional pillars introduced at irregular intervals were unsuccessful in preventing large hangingwall instabilities. This was followed by changing to mining along strike and limiting spans to $20 \mathrm{~m}$ by the use of strike orientated crush pillars. Stiffer support in the form of timber poles replaced the timber composite packs and $3 \mathrm{~m}$ long resin bolts in some areas were implemented as internal support between pillars.

Large hangingwall instabilities continued to be experienced and additional mid-panel pillars were introduced limiting spans to $16 \mathrm{~m}$ along strike. Mid-panel pillars become a standard in 1995 and further limitations span were introduced for south mining. The support installed in between pillars was also changed and the normal timber poles were replaced with modified timber poles (yielding elongates) that yielded in a controlled manner before failure. The $3 \mathrm{~m}$ long resin bolts were replaced by $1.5 \mathrm{~m}$ long grouted rockbolts due to difficulties associated with installing $3 \mathrm{~m}$ long bolts at low stoping heights. Pre-stressing devices were introduced onto the yielding elongates at the end of 1997 in an effort to reduce blast outs during firing of the stope face and increase the initial support stiffness.

Any hangingwall instability exceeding 30 tons or $10 \mathrm{~m}^{2}$ is considered as large. By the end of 2001, eightyone large hangingwall instabilities had been observed. Generally, these falls have been geologically controlled wedges or dome structures that are difficult to identify. For dome failures, the upper size limit appears to be tens of square metres. The dome structures are related to both cooling joints and flat faulting along the VCR lava contact. In some cases, more than one failure mode has been observed with a combination of wedge and dome structures (Figure 1).

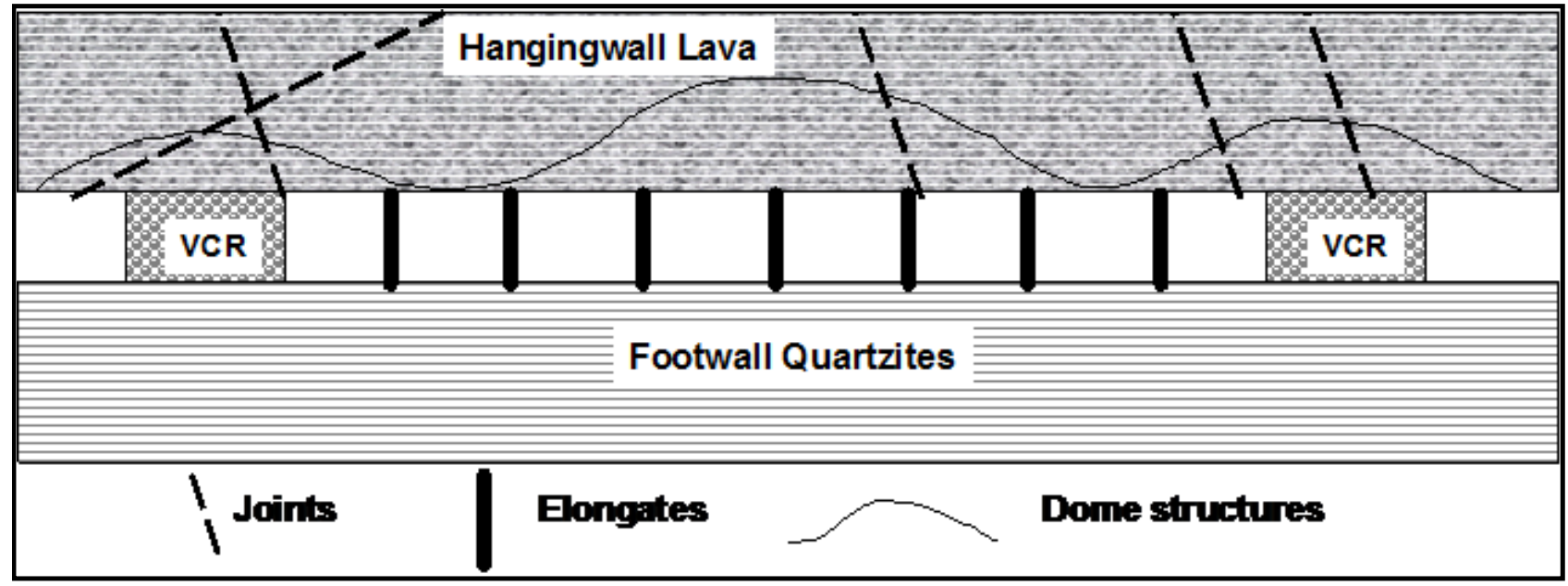

Figure 1 Schematic cross section of a tabular stope showing dome structures and joints in the lava hangingwall with elongate support and VCR pillars

\section{Stable span design}

Stable spans at Tau Lekoa mine are influenced by the span between pillars which controls the maximum instability size (demand) and the capacity of the internal support system which is either timber elongates or 
rockbolts. Maximum spans have been derived from back analysis of large hangingwall instabilities and are based on a relationship between the fallout thicknesses and spans (Judeel and Laas, 1999; Dunn, 2003). By plotting these parameters against each other and using a straight line fit an empirical relationship has been determined (Figure 2). The fallout height was initially estimated to be 0.125 times the span (Rosenblatt, 1994). Later studies have indicated that the fallout height is 0.11 times the span (Judeel and Laas, 1999; Dunn, 2003). For support design purposes, the original factor is used as this provides an additional factor of safety.

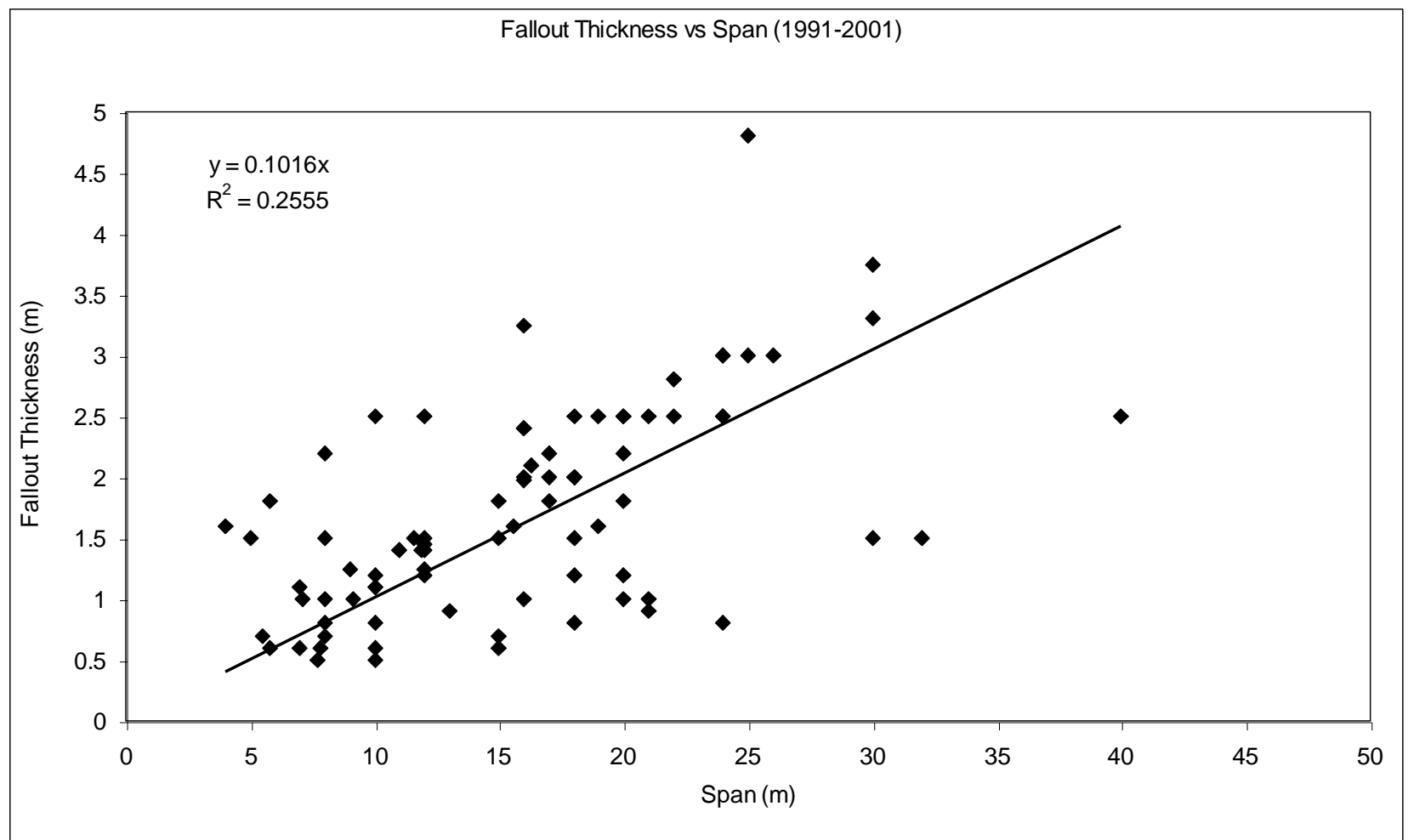

Figure 2 Fallout thickness versus span for the period 1991 to 2001 (after Dunn, 2007)

\section{Back analysis of large instabilities}

To gain a better understanding of large hangingwall instabilities at Tau Lekoa mine a back analysis of 81 large instabilities over a 10 year period, from 1991 to 2001, was conducted. This analysis considered the instability dimensions, geotechnical setting and mining aspects such as mining direction, stoping width and spans. The analysis was conducted for three periods, 1991 to 2001, 1991 to 1994 and 1995 to 2001. A major support change had been implemented in 1995 and the aim was to assess the impact of the revised support strategy.

Statistical methods were used for the back analysis and descriptive statistics and the probability density functions were determined for various parameters using Microsoft ${ }^{\circledR}$ Excel and @RISK with the aim of using this in a risk based design approach (Dunn, 2007).

\subsection{Fallout thickness versus span}

The relationship shown in Figure 2 has a poor correlation with a coefficient of determination $\left(r^{2}\right)$ of 0.26 . The relationship is considered reliable when $r^{2}$ approaches 1 . An analysis was conducted to determine if this relationship varied for north, south or centre gully $(C G)$ mining and if the introduction of mid-panel pillars in 1995 had any influence. The results are summarised in Table 2 and the relationship does not vary markedly although the quality of the fit varies substantially. 
Table 2 Summary of fallout height $(\mathrm{H})$ versus span $(\mathrm{S})$

\begin{tabular}{lccc}
\hline Period & Number of Large Instabilities & Relationship & $\mathrm{r}^{2}$ \\
\hline All: $1991-2001$ & 81 & $\mathrm{~T}=0.1016 \times \mathrm{S}$ & 0.26 \\
All: $1991-1994$ & 18 & $\mathrm{~T}=0.1026 \times \mathrm{S}$ & 0.14 \\
All: $1995-2001$ & 63 & $\mathrm{~T}=0.1009 \times \mathrm{S}$ & 0.13 \\
North: $1991-2001$ & 34 & $\mathrm{~T}=0.1085 \times \mathrm{S}$ & 0.40 \\
North: $1991-1994$ & 4 & $\mathrm{~T}=0.1221 \times \mathrm{S}$ & 0.73 \\
North: $1995-2001$ & 31 & $\mathrm{~T}=0.1039 \times \mathrm{S}$ & 0.16 \\
South: $1991-2001$ & 26 & $\mathrm{~T}=0.0888 \times \mathrm{S}$ & 0.24 \\
South: $1991-1994$ & 9 & $\mathrm{~T}=0.0813 \times \mathrm{S}$ & 0.30 \\
South: $1995-2001$ & 17 & $\mathrm{~T}=0.0951 \times \mathrm{S}$ & 0.49 \\
CG: $1991-2001$ & 21 & $\mathrm{~T}=0.108 \times \mathrm{S}$ & 0.09 \\
CG: $1991-1994$ & 5 & $\mathrm{~T}=0.1136 \times \mathrm{S}$ & 0.18 \\
CG: $1995-2001$ & 15 & $\mathrm{~T}=0.1035 \times \mathrm{S}$ & 0.49 \\
\hline
\end{tabular}

\subsection{Large instability dimensions}

A statistical analysis was conducted for the three periods defined earlier in an attempt to define design input parameters and assess if the introduction of new standards in 1995 had any impact on the large instability dimensions. A distinction was made between different mining directions and for centre gullies.

\subsubsection{Fallout thickness}

Table 3 summarises the statistical data for fallout thickness for the different categories of large instabilities (Dunn, 2007). The probability density function and cumulative distribution are shown in Figure 3. This data can be used to determine support resistance and bolt length requirements. The 95\% cumulative level is commonly used in the design of support in tabular hard rock mining (Daehnke et al., 1998).

Table 3 Summary of fallout thickness statistical data

\begin{tabular}{llllll}
\hline Period & Mean $(\mathrm{Std}$ Dev $)(\mathrm{m})$ & $\mathrm{x}_{\min }(\mathrm{m})$ & $\mathrm{x}_{\max }(\mathrm{m})$ & $95 \%(\mathrm{~m})$ & Fit \\
\hline All:1991-2001 & $1.71(0.86)$ & 0.5 & 4.8 & 3.45 & Inverse gaussian \\
All:1991-1994 & $2.31(1.01)$ & 1.0 & 4.8 & 4.1 & Exponential \\
All:1995-2001 & $1.53(0.73)$ & 0.5 & 3.25 & 2.45 & Beta general \\
North:1991-2001 & $1.67(0.94)$ & 0.5 & 3.75 & 3.26 & Normal \\
North:1991-1994 & $2.99(0.65)$ & 2.4 & 3.75 & 3.7 & Insufficient data \\
North:1995-2001 & $1.48(0.82)$ & 0.5 & 3.25 & 2.8 & Exponential \\
South:1991-2001 & $1.56(0.65)$ & 0.8 & 3.0 & 2.45 & Log logistic \\
South:1991-1994 & $1.71(0.62)$ & 1.0 & 2.5 & 2.48 & Beta general \\
South:1995-2001 & $1.49(0.67)$ & 0.8 & 3.0 & 2.5 & Exponential \\
CG:1991-2001 & $1.94(0.93)$ & 0.6 & 4.8 & 3.0 & Ext value \\
CG:1991-1994 & $2.86(1.26)$ & 1.5 & 4.8 & 4.45 & Beta general \\
CG:1995-2001 & $1.60(0.58)$ & 0.6 & 2.5 & 2.4 & Ext value \\
\hline
\end{tabular}




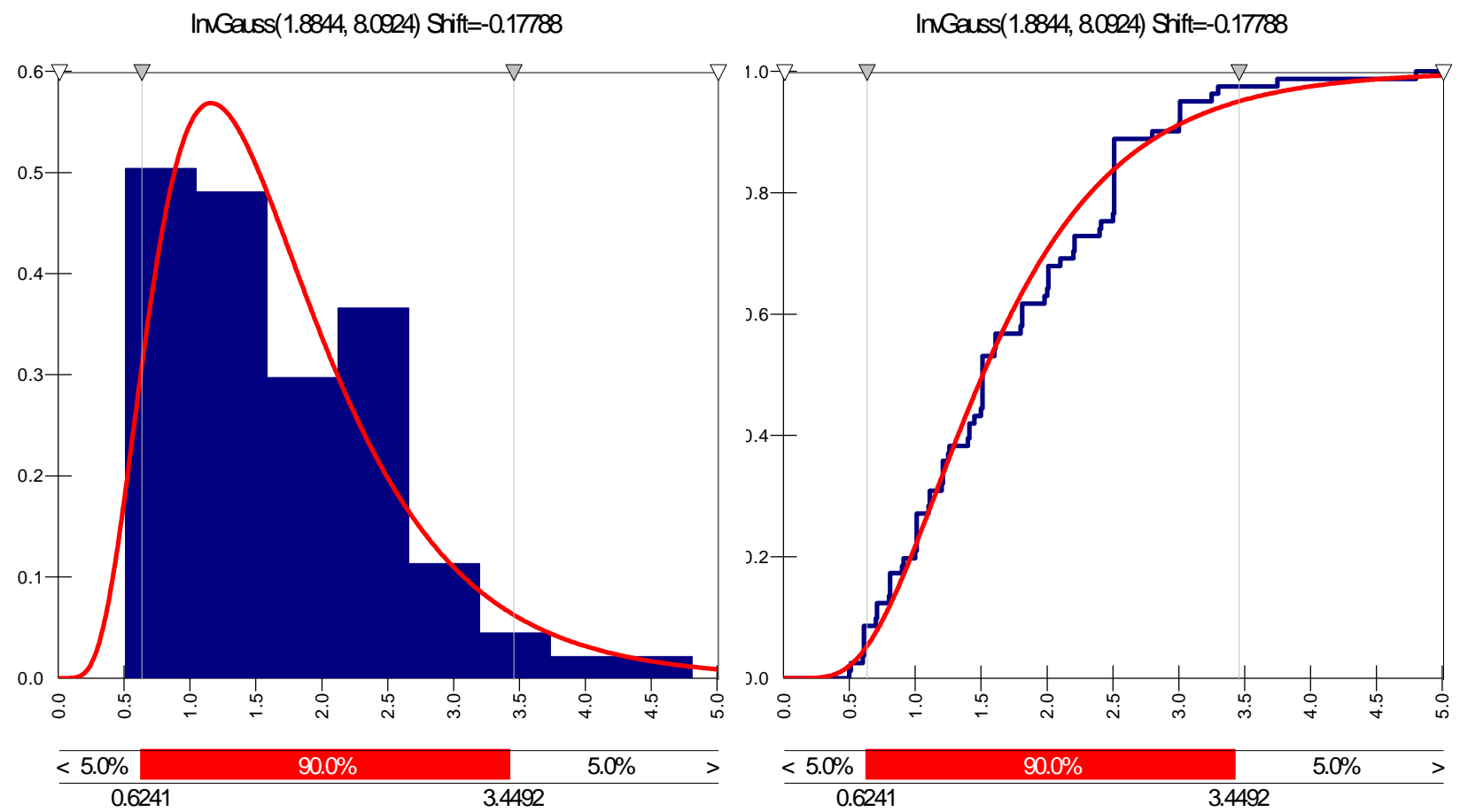

Figure 3 Probability density function and cumulative distribution for large FOG thickness (1991-2001)

\subsubsection{Large instability length and width}

Table 4 summarises the statistical data for large instability length and width which have been combined to determine the large instability dimension for the different categories of large instabilities (Dunn, 2007). This can be used to determine stope support requirements.

Table 4 Large instability dimension summary

\begin{tabular}{llllll}
\hline Period & Mean $(\operatorname{Std} \operatorname{Dev})(\mathrm{m})$ & $\mathrm{x}_{\min }(\mathrm{m})$ & $\mathrm{x}_{\max }(\mathrm{m})$ & $95 \%(\mathrm{~m})$ & Fit \\
\hline All:1991-2001 & $12.5(8.0)$ & 2.5 & 43 & 28.9 & Log normal 2 \\
All:1991-1994 & $14.1(7.5)$ & 3.0 & 36 & 24.8 & Logistic \\
All:1995-2001 & $12.1(8.1)$ & 2.5 & 43 & 25 & Inverse gaussian \\
North:1991-2001 & $12.8(8.9)$ & 2.5 & 40 & 32.5 & Log logistic \\
North:1991-1994 & $22.8(9.1)$ & 14 & 36 & 35 & - \\
North:1995-2001 & $11.0(8.0)$ & 2.5 & 40 & 24 & Exponential \\
South:1991-2001 & $12.1(7.0)$ & 3.0 & 43 & 23.9 & Log logistic \\
South:1991-1994 & $12.0(4.83)$ & 3.0 & 19 & 18.1 & Ext value \\
South:1995-2001 & $12.4(8.0)$ & 3.2 & 43 & 24.5 & Log logistic \\
CG:1991-2001 & $12.7(7.7)$ & 3.0 & 40 & 23 & Ext value \\
CG:1991-1994 & $11.6(5.2)$ & 3.0 & 21 & 20.5 & Beta general \\
CG:1995-2001 & $12.7(8.5)$ & 4.0 & 40 & 31 & Inverse gaussian \\
\hline
\end{tabular}




\subsection{Geotechnical and mining setting}

Several relationships relating to the geotechnical setting and mining have been identified on Tau Lekoa mine and these were further analysed to assess their validity.

\subsubsection{Depositional environment}

Six depositional environments have been identified at Tau Lekoa mine (Frith, 1998). Biddulph (1999) investigated the spatial distribution of large hangingwall instabilities by superimposing them on the depositional model. It was concluded that the majority of these instabilities occurred in Main Channel areas. It was postulated that this could be due to the Unit 1 lavas that overlay the Main Channel or possibly related to the large structures flanking these areas. This was further analysed as the following two factors are considered relevant:

- A large proportion of the early mining was in the Main Channel.

- Support standards prior to 1995 were different.

For the period 1991 to 2001 it was found that $77 \%$ of large stabilities occurred in the Main Channel. The number of large instabilities were normalised against production (area mined) for the period 1996 to 2001 and this is summarised in Table 5. From this it can be seen that the majority of instabilities occur in the Main Channel and there is a higher likelihood of a large instability occurring expressed as the area mined per large instability.

Table 5 Breakdown of large FOG per geo-zone normalised against production for 1996 to 2001

\begin{tabular}{lccc}
\hline Geo-zone & $\begin{array}{c}\text { Number of } \\
\text { Instabilities }\end{array}$ & \% Instabilities & $\begin{array}{c}\text { Area mined } \\
\left(\mathrm{m}^{2}\right) / \text { Instability }\end{array}$ \\
\hline Main Channel (MC) & 39 & 67 & 10100 \\
Reworked Channel (RC) & 8 & 14 & 67825 \\
Middle Terrace Conglomerate (MTC) & 5 & 9 & 125457 \\
Middle Terrace and Slopes (MTS) & 5 & 9 & 45078 \\
Upper Terrace (UT) & 1 & 2 & 216565 \\
Total & 58 & 100 & 34582 (average) \\
\hline
\end{tabular}

\subsubsection{Stoping width}

Judeel and Laas (1999) observed that higher stope widths (mining height) were more hazardous in terms of large instabilities. It was found that there was a higher relative incidence of large instabilities at stoping widths greater than $1.8 \mathrm{~m}$ even though the bulk of stoping was at a lower stoping width. The $1.8 \mathrm{~m}$ stoping width was chosen as a boundary because this is the upper limit for the timber elongate support used at Tau Lekoa mine. When this stoping width limit is exceeded, the support is changed to rockbolts and spans are reduced to $10 \mathrm{~m}$.

This analysis was revised to include the additional data and it was found that approximately $44 \%$ of large instabilities occurred at a stoping width greater than $1.8 \mathrm{~m}$ even though stoping at greater than $1.8 \mathrm{~m}$ only accounts for $15 \%$ of mining at Tau Lekoa mine. Stoping width is controlled by channel width and it was observed that higher channel widths are associated with the main channel and reworked channel.

\subsubsection{Mining direction}

Problems associated with mining in a southerly direction have been experienced since the beginning of mining at Tau Lekoa mine (Judeel and Laas, 1999). Where possible south mining is avoided and, where it is unavoidable, more stringent standards are applied with reduced spans and increased internal support. 
South mining makes up about 35\% of the mining at Tau Lekoa mine. Table 6 shows the actual large instabilities and the expected number normalised for production in south mining panels. Generally, there is a higher chance of having a large FOG in a south mining panel (Dunn, 2007).

Table 6 Actual versus expected large instabilities in south mining

\begin{tabular}{lcccccc}
\hline & \multicolumn{2}{c}{$1991-2001$} & \multicolumn{2}{c}{$1991-1994$} & \multicolumn{2}{c}{$1995-2001$} \\
\hline North & South & North & South & North & South \\
Expected & 34 & 26 & 4 & 9 & 30 & 17 \\
\% Increase & - & 18 & - & 2 & - & 17 \\
\hline
\end{tabular}

\subsubsection{Mining depth}

The influence of depth on the occurrence of large instabilities was investigated and Figure 4 shows that the majority of large instabilities occurred on 1200 and 1350 levels. Early mining was concentrated on the upper levels and as mining progressed deeper new standards were introduced in 1995. This could be the reason why there is a reduction in the number of large instabilities with increasing mining depth. It is also possible that the failure mechanism has changed with stress induced failure becoming more dominant that geological controlled failure with increasing depth. Further analysis is required to confirm these preliminary conclusions (Dunn, 2007).

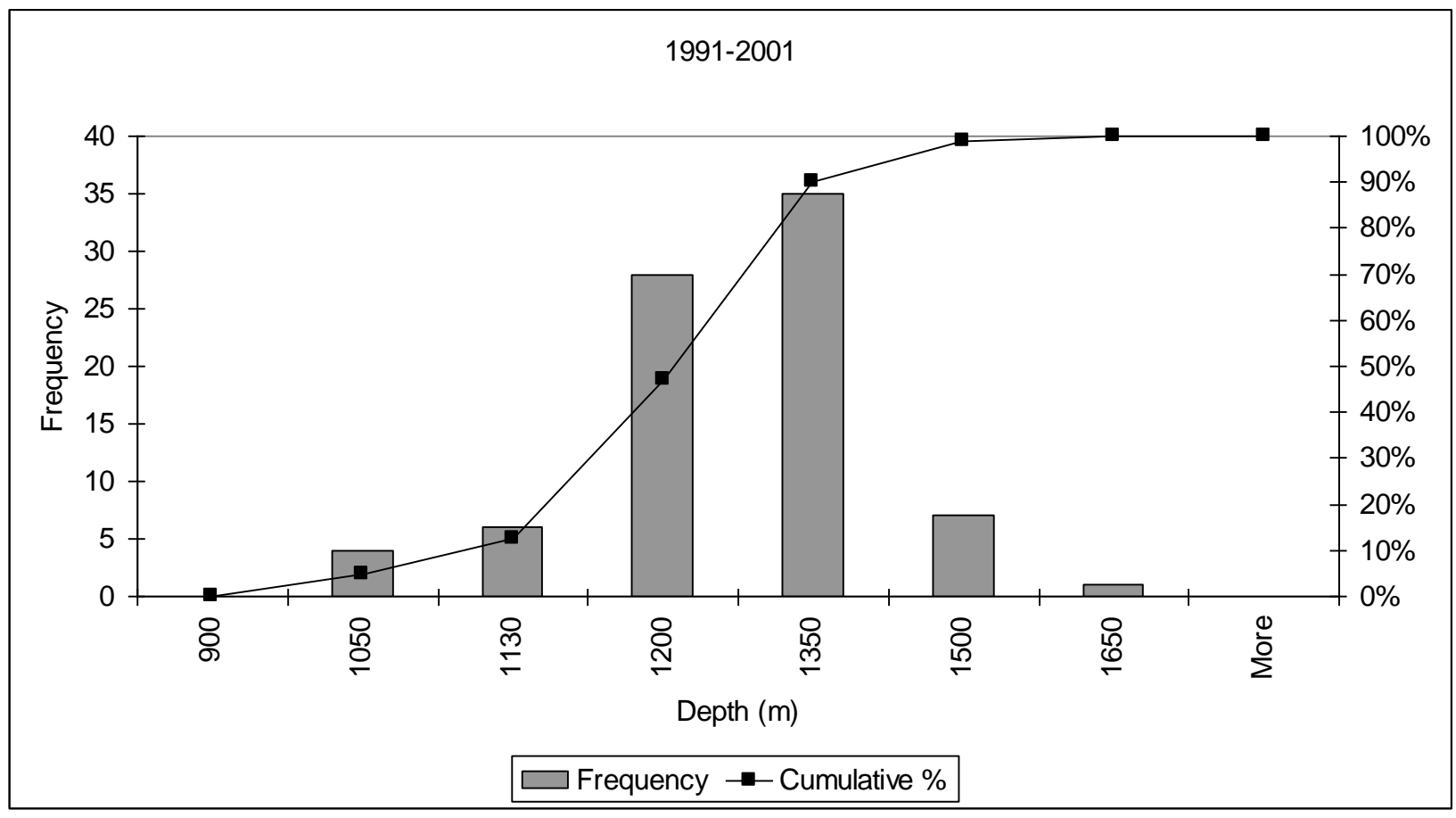

Figure 4 Distribution of large hangingwall instabilities with mining depth for 1991-2001

\subsubsection{Mining spans}

An analysis was conducted of the mining spans at which large instabilities had occurred and the applicable span standard at the time. Prior to 1995 the $20 \mathrm{~m}$ span standard was exceeded for $60 \%$ of the large instabilities. After 1995, 35\% of large instabilities occurred at spans greater than the $16 \mathrm{~m}$ standard. Of concern was the number of instabilities at spans less than the required standard span indicating shortcomings in the internal support system. 
Spans were measured from mine plans over a period of 20 months (March 2000 to November 2001). For north mining at stoping widths exceeding $1.8 \mathrm{~m}$ the span requirement of $10 \mathrm{~m}$ was exceeded $59 \%$ of the time. For north mining at stoping widths below $1.8 \mathrm{~m}$ the $16 \mathrm{~m}$ span requirement was exceeded $24 \%$ of the time. The $10 \mathrm{~m}$ span requirement for south mining was exceeded $56 \%$ of time.

\section{$4 \quad$ Probabilistic keyblock analysis}

A probabilistic keyblock analysis was conducted to evaluate hangingwall stability for different spans and internal support using JBlock software (Esterhuizen, 1996; Esterhuizen and Streuders, 1998). JBlock was developed to evaluate the potential for gravity driven rock falls using probabilistic methods to determine potential keyblock dimensions and their interaction with support. Geological information such as the spacing, orientation and length of discontinuities is used to simulate blocks in the walls of an excavation. Keyblock analysis methods (Goodman and Shi, 1985) are used to evaluate whether blocks are removable and whether the chosen support will be sufficient to ensure stability.

JBlock allows the user to conduct a single block analysis or a multi-block analysis. For a multi-block analysis, the discontinuity information is used to generate a set number of blocks independently of each other. Normally JBlock is used to evaluate the stability of smaller scale blocks however, in this case an attempt was made to simulate larger blocks. Information on the large instability dimensions from the back analysis was used as a guideline in determining the geological input parameters for this modelling.

\subsection{Modelling approach}

JBlock can only model the stability of blocks and strictly speaking dome structures are not taken into account. It could be argued that the dome structures approximate a truncated pyramid or polyhedral shaped blocks which are generated by JBlock and are thus accounted for. JBlock allows the user to generate a set of blocks that can be saved and used to assess the stability of different pillar layouts and internal support systems.

The joint information from Table 1 was used to generate 10,000 blocks. Discontinuity length and spacing govern the block sizes and the inputs were based on the mean, minimum and maximum of data for large instabilities. A number of block sets were generated and the stability was evaluated for different mining directions, spans and support standards.

From the first set of blocks generated (Normal Blocks), it was noticed the majority of blocks were substantially smaller than the large instabilities observed. Two further block sets were generated, for Large Blocks-1 the mean and minimum joint lengths where increased and for Large Blocks-2, the joint spacing was also increased in an effort to generate larger blocks. Figure 5 shows the distribution of keyblock sizes.

For Large Blocks-1 and Large Blocks-2, it can be seen that a number of larger blocks have been generated although these blocks are still smaller than the largest instability observed. Approximately $65 \%$ of large instabilities observed at Tau Lekoa mine have a volume of $300 \mathrm{~m}^{3}$ or less. The number of larger blocks generated is relatively small. However, over 10 years of mining, 81 large instabilities were observed and 2.78 million square metres were mined. The total cumulative area of the large instabilities during that period is $15,338 \mathrm{~m}^{2}$ which is less than $1 \%$ of the total area mined indicating that the small percentage of large blocks generated by JBlock is not unrealistic.

Ten different panel layouts were modelled considering different mining directions and pillar spans (Table 7). A total of 40 model runs were conducted for this analysis. Elongates were used as the internal support and these were assigned a peak load of $150 \mathrm{kN}$. This is substantially lower than the peak loads generated by the $180 \mathrm{~mm}$ diameter profile props under laboratory conditions. The peak load was downgraded to take into account the lower in situ loading rates, timber variability and deterioration over time. The support spacing used was $1.5 \mathrm{~m}$ on strike and $2 \mathrm{~m}$ on dip as per the mine standards. A series of models was run with an increased support capacity of $300 \mathrm{kN}$ to determine the impact of increased internal support resistance. 


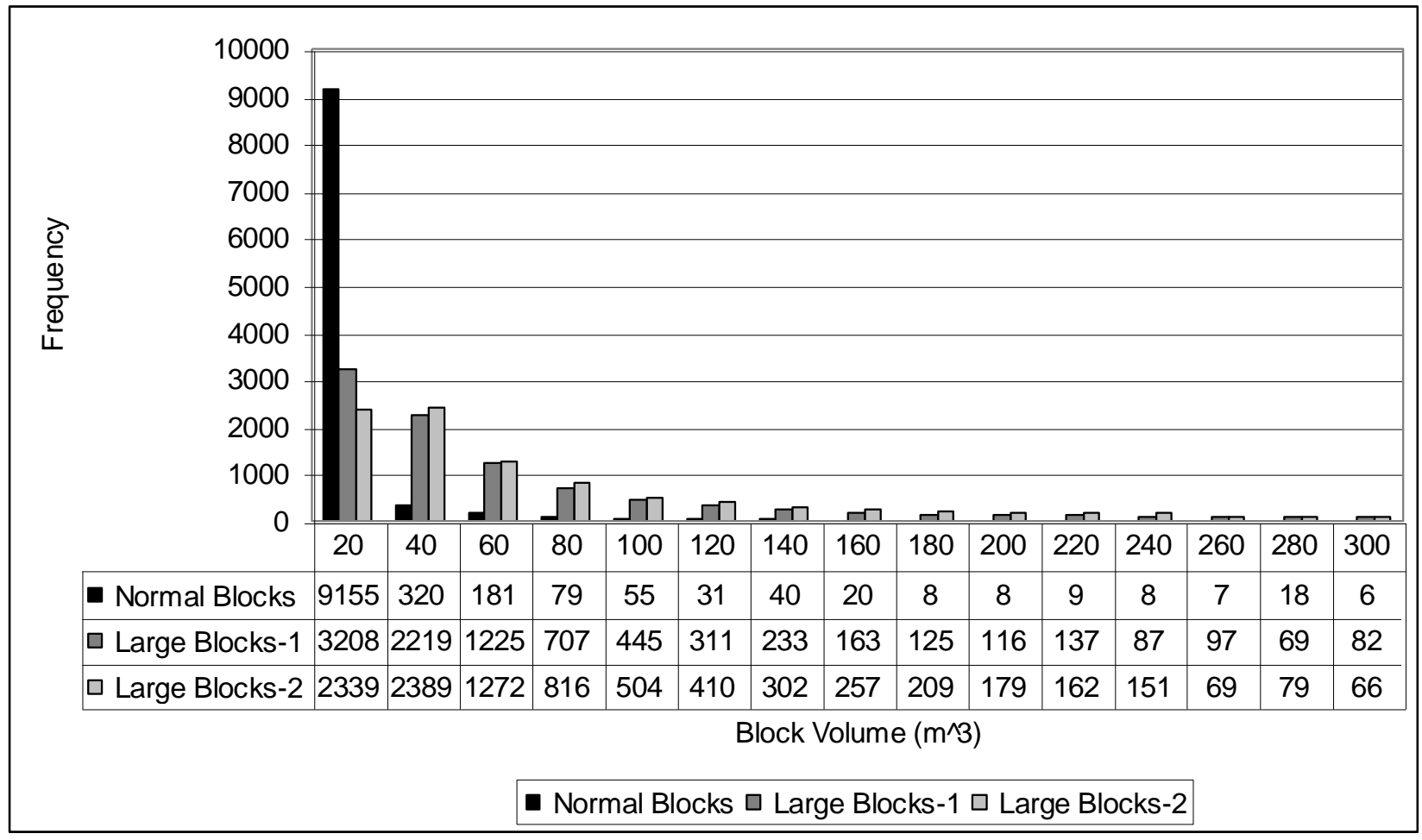

Figure 5 Block size distribution for the three block sets generated using JBlock

Table 7 Panel face lengths and mid-panel pillar spans

\begin{tabular}{lccc}
\hline Description & Direction & Face Length $(\mathrm{m})$ & Mid-panel Pillar Span $(\mathrm{m})$ \\
\hline North 10 & North & 20 & 10 \\
North $10-30$ & North & 30 & 10 \\
North 16 & North & 20 & 16 \\
North $16-30$ & North & 30 & 16 \\
North 24 & North & 20 & 24 \\
North $24-30$ & North & 30 & 24 \\
South 10 & South & 20 & 10 \\
South $10-30$ & South & 30 & 10 \\
South 15 & South & 20 & 15 \\
South $15-30$ & South & 30 & 15 \\
\hline
\end{tabular}

\subsection{Probabilistic keyblock modelling results}

Tables showing the probabilities of support failure per block size are generated in JBlock but were found to be difficult to analyse. The probabilities per block size were summed to allow easy comparisons (Figure 6). The summed probabilities shown are indicative only and not the real probabilities of failure but a means of comparison.

It can be seen that the probability of support failure increases with increasing span for all three block sets. From this modelling, it appears that south mining is less hazardous although the spans used were slightly different. This analysis showed span rather than mining direction influenced stability. It is possible to substantially reduce the probability of support failure by increasing the internal support capacity and this is an option which should be explored further. 


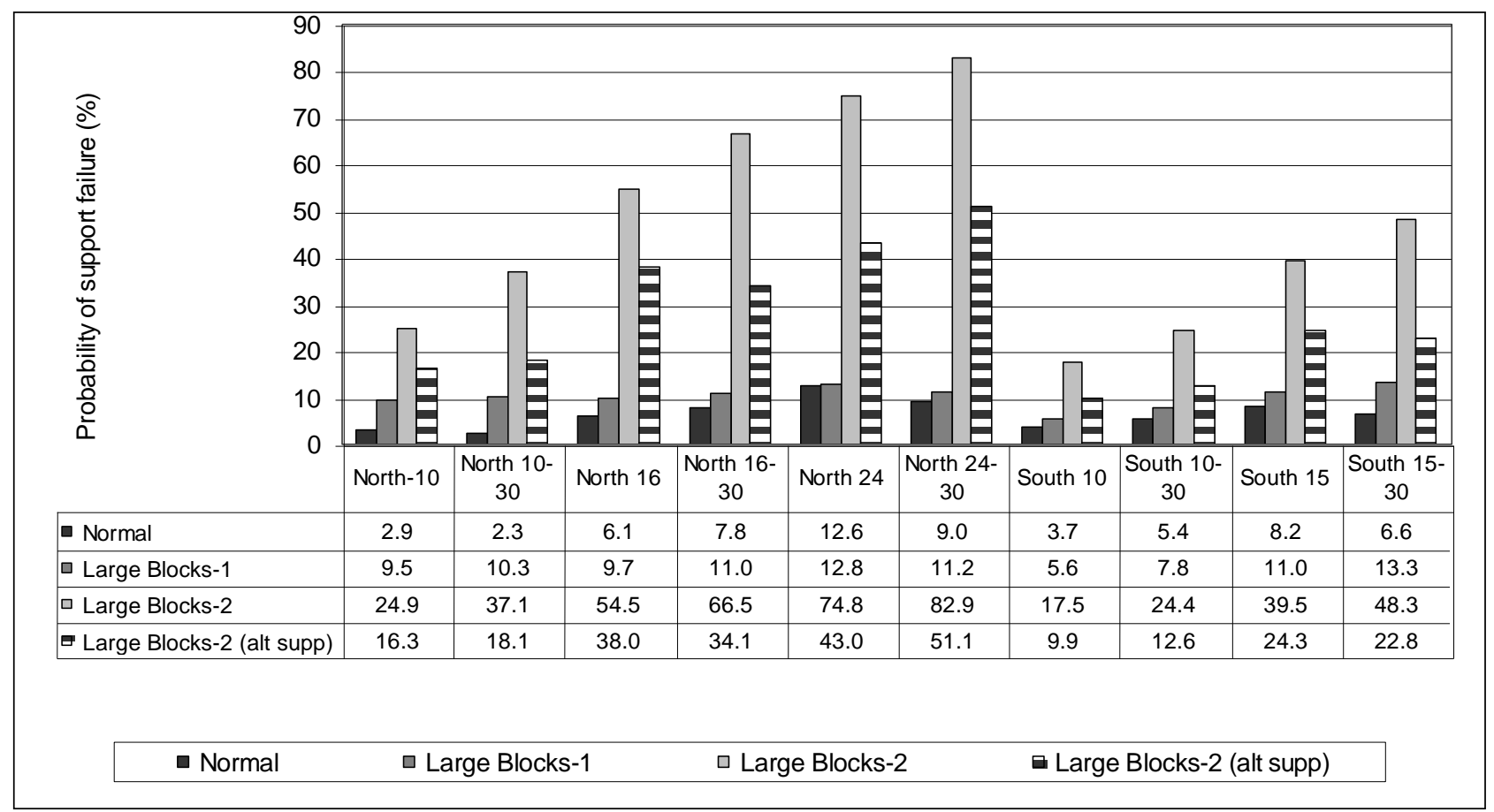

Figure 6 Comparison of summed probabilities of support failure

\section{Controlling large hangingwall instabilities}

The probability of occurrence of a large instability can be assessed using the simplified cause tree shown in Figure 7. For a large hangingwall instability to occur it is necessary for a large wedge or dome structure to occur in between the crush pillars used to limit spans at Tau Lekoa mine. Experience at the mine indicates that this has occurred relatively often. This is supported by the probabilistic keyblock modelling which demonstrates that large blocks can occur and that probabilities of failure of up to $10 \%$ were determined for some block volumes. The fact that standard spans are often exceeded also increases the likelihood of a large wedge or dome structure occurring in between pillars.

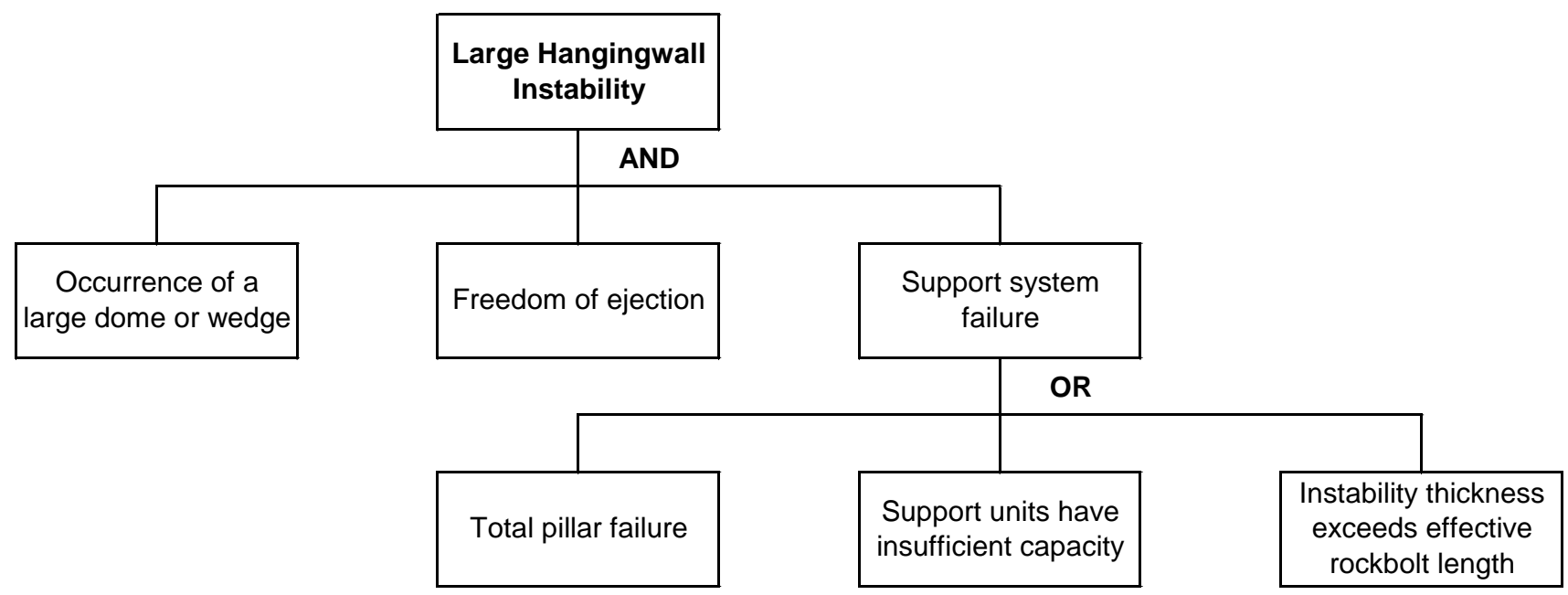

\section{Figure 7 Cause tree showing factors that contribute to large hangingwall instabilities}

In this paper, the possibility of the internal support capacity being exceeded by block demand is discussed. The potential fallout thickness at Tau Lekoa mine is estimated to be 0.125 times the span and internal support is required to support a thickness of 1.25 and $2 \mathrm{~m}$ for spans of 10 and $16 \mathrm{~m}$ respectively. The support resistance requirements are shown in Table 8. 
Table 8 Back area support resistance requirements (Dunn, 2007)

\begin{tabular}{ccc}
\hline Span $(\mathrm{m})$ & Potential Fallout Thickness $(\mathrm{m})$ & SR Requirement $\left(\mathrm{kN} / \mathrm{m}^{2}\right)$ \\
\hline 10 & 1.25 & 33 \\
16 & 2 & 53 \\
\hline
\end{tabular}

\subsection{Stoping widths less than $1.8 \mathrm{~m}$ supported using timber profile props}

To satisfy the support resistance criteria profile props with a peak capacity of $250 \mathrm{kN}$ are used at a spacing of $1.5 \mathrm{~m}$ on strike and $2 \mathrm{~m}$ on dip. This provides a support resistance of $83 \mathrm{kN} / \mathrm{m}^{2}$, which is sufficient to support a thickness of $3.1 \mathrm{~m}$ (Dunn, 2007). In reality, it is unlikely that this support resistance is achieved underground as the in situ loads achieved by timber profile props are generally lower due to the slower loading rate. Timber strength is also highly variable and markedly influenced by moisture content, presence of cracks and stoping height. The unit performance and quality of support installation and actual installed spacing determines the real support resistance. For the JBlock analysis, the unit loads were downgraded to $150 \mathrm{kN}$ to account for these factors.

Figure 8 shows the height distribution and cumulative percentage for blocks generated using JBlock. Eighty-two per cent of the blocks have a height in excess of $3 \mathrm{~m}$ although many of these blocks are stable. This shows that it is quite possible that the internal support capacity can be exceeded. This was shown in the JBlock analysis which indicated that support failure by keyblocks occurred quite often and the probability of support failure increased with increasing span.

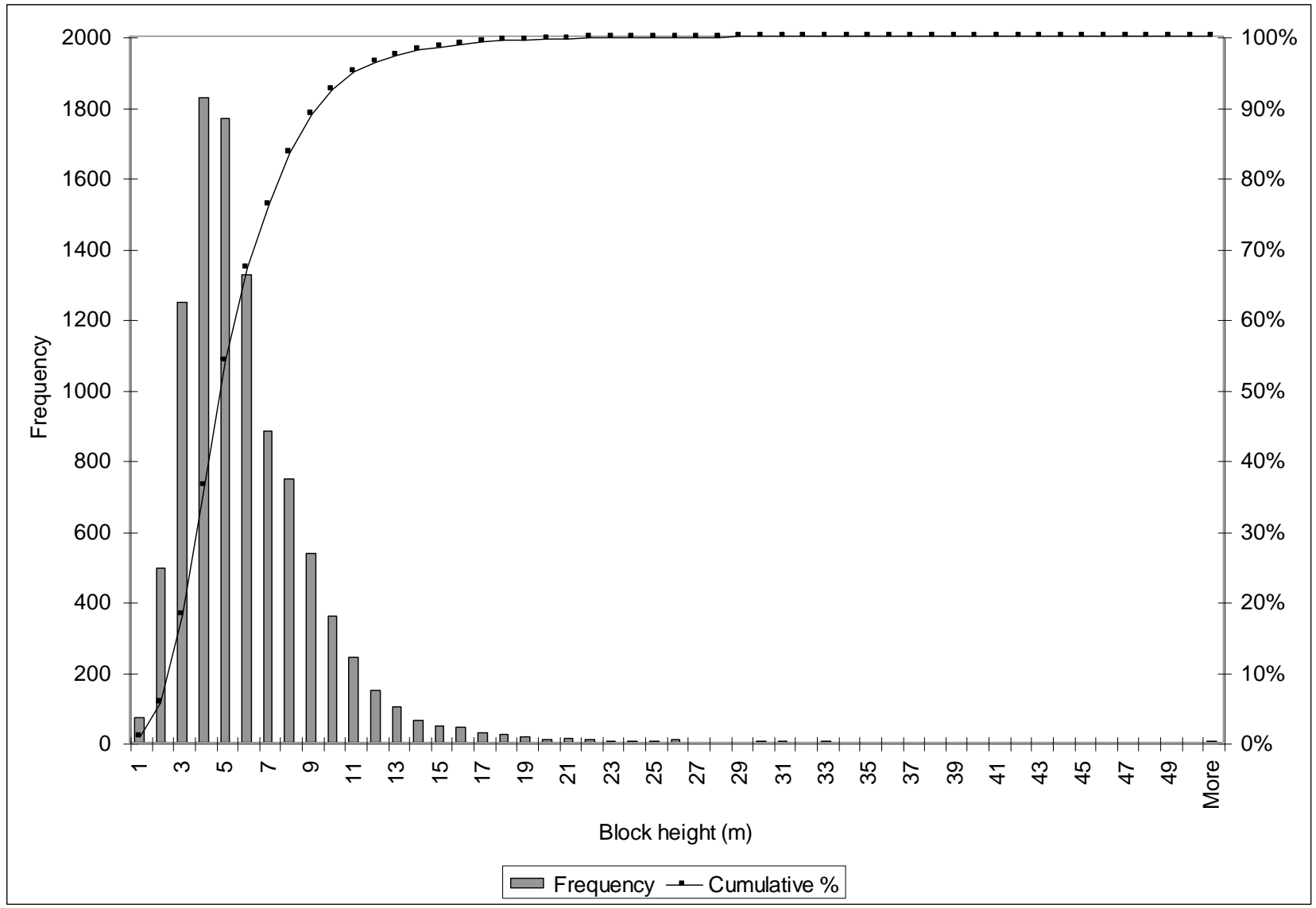

Figure 8 Block height distribution and cumulative percentage from JBlock (Large Blocks-2) 


\subsection{Stoping widths greater than $1.8 \mathrm{~m}$ supported with rockbolts}

For stoping widths greater than $1.8 \mathrm{~m}$ the span is reduced to 10 and $1.5 \mathrm{~m}$ long end anchored rockbolts with a capacity of $170 \mathrm{kN}$ are used at a spacing of $1.5 \mathrm{~m}$ on strike and $2 \mathrm{~m}$ on dip providing a support resistance of $57 \mathrm{kN} / \mathrm{m}^{2}$. Based on the fallout thickness versus span relationship the rockbolts have to cater for a thickness of $1.25 \mathrm{~m}$ and the standard exceeds the support resistance requirement shown in Table 8 (Dunn, 2007).

This design relies on suspension as a mechanism and end anchored bolts are only able to support rock situated below the end anchor. With a perfect installation at $90^{\circ}$ to the hangingwall, it would be possible to support a $1.4 \mathrm{~m}$ thickness. In reality, the bolts are installed at about $70^{\circ}$ and are only able to support a thickness of about $1.3 \mathrm{~m}$.

Figure 9 shows the deviation from the thickness predicted using the empirical relationship and the actual thickness measured for the 81 large instabilities. This shows that the predicted thickness is exceeded $27 \%$ of the time and the effective bolt length of $1.3 \mathrm{~m}$ is exceeded $20 \%$. Figure 8 indicates that $95 \%$ of the blocks generated using JBlock have heights exceeding the thickness the support is capable of supporting although many of the blocks generated are stable.

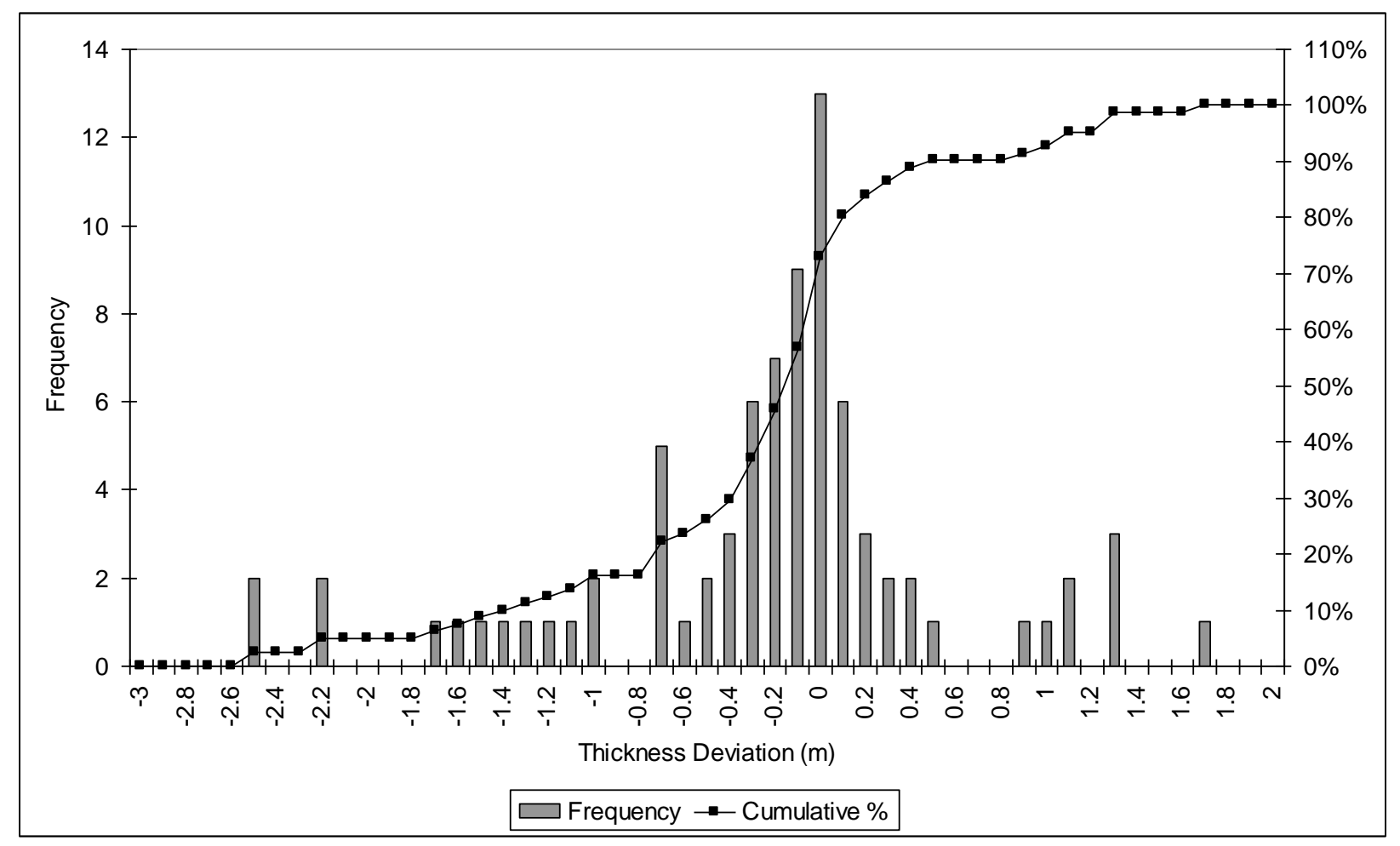

Figure 9 Deviation of actual thickness from predicted thickness for large instabilities

\section{Discussion and conclusions}

The empirical relationship between fallout thickness and span can be considered unreliable, especially when it is considered that both probabilistic keyblock modelling and actual instability thicknesses often exceed the predicted thickness. Possibly a more conservative approach should be used for internal support design such as the 95\% cumulative thickness of large stabilities shown in Table 3.

Alternatively an appropriate percentage cumulative level for the factor relating fallout thickness to span could be used as shown in Figure 10. At an $80 \%$ cumulative level, thicknesses of 1.3 and $2.1 \mathrm{~m}$ would have to be supported for 10 and $16 \mathrm{~m}$ spans respectively. For a 95\% cumulative level, thicknesses of 2.5 and $4 \mathrm{~m}$ would have to be supported for 10 and $16 \mathrm{~m}$ spans respectively. 


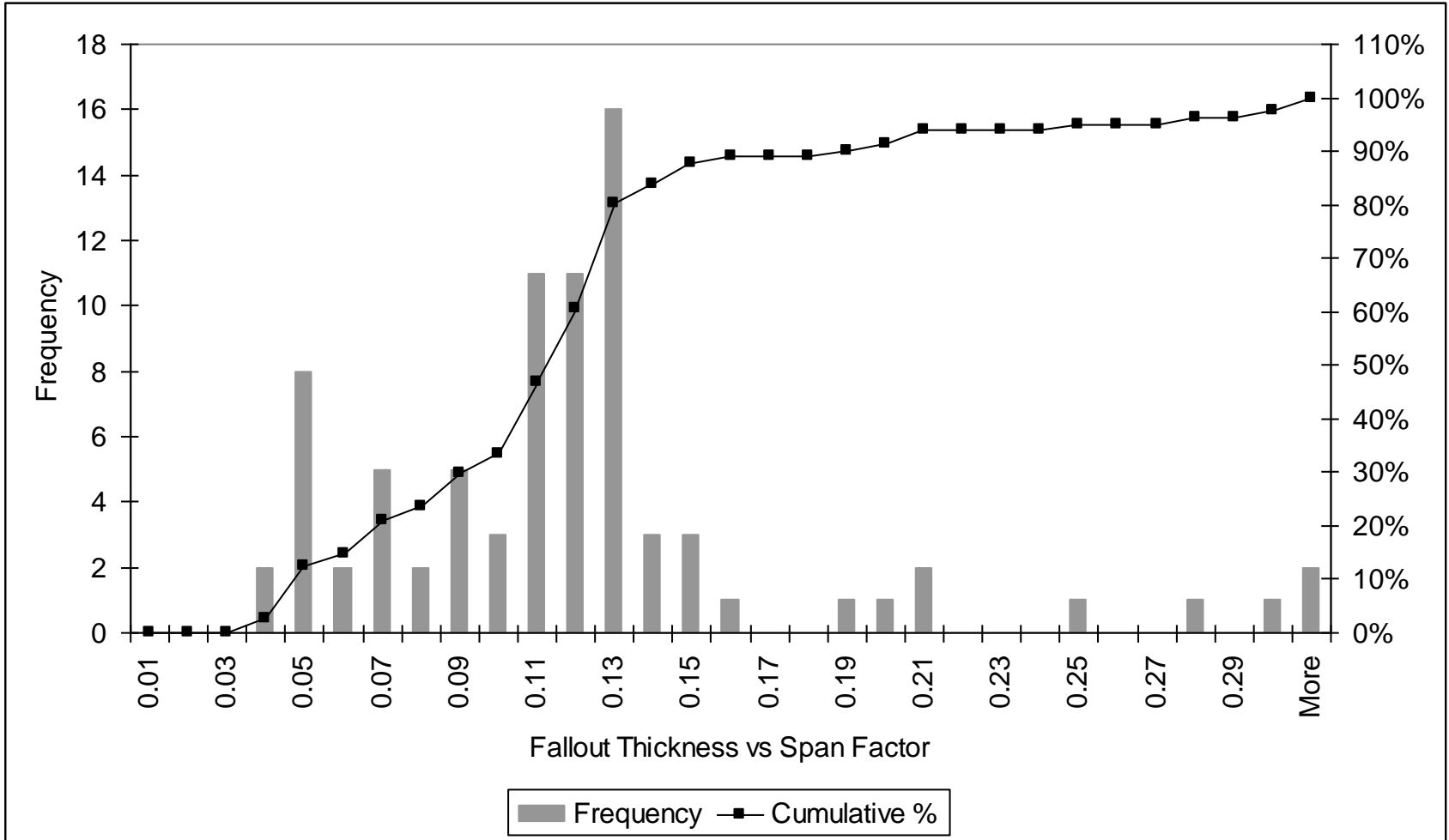

Figure 10Cumulative fallout thickness versus span factor

There appears to be a higher likelihood of large hangingwall instabilities when mining in the Main Channel or at higher stoping widths. There has been a decrease in the occurrence of large instabilities with an increase in mining depth. It is unclear whether this is related to mining outside of the Main Channel, the introduction of more stringent support standards in 1995 or a change in failure mechanisms with depth and this is an area requiring further work.

There is evidence suggesting that mining in a southerly direction is more hazardous although this is mainly related to large instabilities prior to 1995. From the JBlock modelling it appears that spans have a greater influence on hangingwall instabilities than mining direction.

The JBlock modelling also highlighted the fact that improved internal stope support could reduce the probability of hangingwall instability. This should be explored further by means of a cost benefit analysis that considers different support and span options in terms of increased recoveries or improved mining efficiencies.

It has been shown that there is a relatively high likelihood that the demand of large hangingwall wedges or domes will exceed the capacity of the internal support system. A revised design approach with improved design criteria is needed to ensure that there is adequate internal support and this likelihood is reduced.

A simple cause tree for large hangingwall instabilities has been developed and this could be used as part of a risk based design approach. Data collected and analysed as part of this study and the main conclusions could be used in a risk based design.

\section{Acknowledgements}

The authors would like to thank AngloGold Ashanti for permission to conduct and publish this work. 


\section{References}

Biddulph, M.N. (1999) Implications of the geological model on safety at Tau Lekoa Mine. Internal AngloGold Report. Daehnke, A., Andersen, L.M., de Beer, D., Esterhuizen, G.S., Glisson, F.J., Grodner, M.W., Hagan, T.O., Jaku, E.P., Kuijpers, J.S., Peake, A.V., Piper, P.S., Quaye, G.B., Reddy, N., Roberts, M.K.C., Schweitzer, J.K., Stewart, D.R. and Wallmach, T.R. (1998) Stope face support systems. Project GAP330 SIMRAC.

Dunn, M.J. (2003) The determination of stable inter-pillar spans at Tau Lekoa Mine. Proceedings of the 10th ISRM Congress, SAIMM, Johannesburg, pp. 261-266.

Dunn, M.J. and Stacey, T.R. (2006) Stable pillar spans at Tau Lekoa Mine. The 41st U.S. Symposium on Rock Mechanics (USRMS): 50 Years of Rock Mechanics - Landmarks and Future Challenges, Golden, Colorado.

Dunn, M.J. (2007) Design of stable inter-pillar spans at Tau Lekoa Mine. MSc. Project report. Unpublished. University of the Witwatersrand.

Esterhuizen, G.S. (1996) JBlock User's Manual and Technical Reference.

Esterhuizen, G.S. and Streuders, S.B. (1998) Rockfall hazard evaluation using probabilistic keyblock analysis. Jour. S. Afr. Inst. Min. Metall. March/April, pp. 59-63.

Fourie, C. (1999) Implications of variable lava strengths on the hangingwall stability at Tau Lekoa. Internal AngloGold Report.

Frith, I. (1998) Developments to the VCR facies model at Tau Lekoa Mine. Presentation for the AngloGold Senior Geologists Conference.

Goodman, R.E. and Shi, G. (1985) Block theory and its application in rock engineering. Prentice Hall.

Judeel, G. and Laas, J.J. (1999) An empirical method for the determination of the fall out height versus span between crush pillars at AngloGold - Tau Lekoa Mine. 2nd Southern Africa Rock Engineering Symposium, In Implementing Rock Engineering Knowledge, T.O. Hagan (editor), SANIRE, Johannesburg, pp. 28-36.

Lombard, J.J. (1989) Rock Mechanics strategy for 10 shaft. Internal AngloGold Report.

Rosenblatt, M. (1994) Support strategy - Vaal Reefs No. 10 Shaft. Internal AngloGold Report. 